\title{
The influence of non-pharmacological management of obesity on a diurnal blood pressure profile
}

\author{
Justyna Widecka', Katarzyna Widecka-Ostrowska', Joanna Ziemak', Anna Brzeska', \\ Tomasz Miazgowski', Krystyna Widecka'
}

\author{
'Department of Hypertension and Internal Diseases, Pomeranian Medical University in Szczecin \\ ${ }^{2}$ Department of Cardiology, Pomeranian Medical University in Szczecin
}

\begin{abstract}
Background. Obesity is one of the main factors increasing mortality and the incidence of diseases of the cardiovascular system. The base treatment is a non-pharmacological approach: diet and physical training. We see hypertension in obese people more often than in people of normal weight. The aim of this study was to answer the question of whether or not a 3-month comprehensive program of non-pharmacological treatment of obesity affects the circadian blood pressure profile.

Material and methods. The study was performed with 60 obese women aged 20-37 years who had an average body mass index (BMI) of $36 \pm 4.9 \mathrm{~kg} / \mathrm{m}^{2}$ and who declared their willingness to participate in the treatment of obesity. Qualified researchers proposed participation in the comprehensive, outpatient, non-pharmacological treatment program for obesity. The program included activities with a dietician, physiotherapist and physician. Patients performed blood pressure measurements using 24-hour ambulatory monitoring (ABPM).

Results. After 3 months of treatment, the participants had a significant decrease in BMI and waist circumference. These changes were accompanied by a significant reduction in fasting insulin concentrations and a decrease in the insulin resistance index. Findings also showed a small but significant reduction in systolic blood pressure - circadian, daytime and nighttime - and a reduction in the incidence characteristics of of 'non-dipper' pattern. In the study group significant positive correlations were found between the change in fasting insulin concentration and the change in circadian systolic blood pressure.

Conclusion. A non-pharmacological, comprehensive treatment program for obesity through weight reduction and a reduction of insulin resistance improves the profile of circadian systolic blood pressure and leads to the conversion of 'non-dipper' pattern to favourable 'dipper' pattern.

key words: management of obesity, blood pressure profile, blood pressure variability, ambulatory blood pressure
\end{abstract}

Arterial Hypertens. 2016, vol. 20, no. 2, pages: 68-72

DOI: $10.5603 / A H .2016 .0011$

Address for correspondence: Prof. dr hab. n. med. Krystyna Widecka

Klinika Hipertensjologii i Chorób Wewnętrznych, Pomorski Uniwersytet Medyczny

ul. Unii Lubelskiej 1, 71-252 Szczecin

tel.: (091) 425-35-50, fax: (091) 425-35-52

e-mail: widecka@o2.pl

V M Copyright $@ 2016$ Via Medica, ISSN 2449-6170 


\section{Introduction}

Obesity is one of the largest health problems in a consumer society as it leads to many complications, mainly involving the cardiovascular system, and is associated with increased mortality $[1,2]$. In 1998, the World Health Organization (WHO) identified obesity as a multifactorial chronic disease [3]. Increasing frequency of its occurrence is caused by the easy availability and excessive supply of food, a sedentary lifestyle and lack of exercise.

In the Pol-MONICA, area of Poland, we found obesity was prevalent in about $30 \%$ of women and $20 \%$ of men $[4,5]$. The goal of treatment of obesity is to reduce body weight by $5-10 \%$, which is considered a sufficient weight loss to bring about health benefits. The time in which the target should be achieved is 3-6 months [6, 7].

It has been proven in a number of studies that weight loss of $5-30 \%$ can effectively reduce blood pressure, abnormal carbohydrate alignment and dyslipidaemia, and thus reduce the risk of complications of obesity and reduce mortality [8-10]. Hypertension is seen in obese people more often than in people of normal weight. It is believed that the predisposition to hypertension does not correspond to obesity or metabolic disorders but it involves, above all, hyperinsulinaemia, insulin resistance and leptin resistance [11-15].

The organ complications and risk of cardiovascular events in the case of hypertension are determined not only by its absolute value but also its short-term and circadian variability $[16,17]$. Ambulatory blood pressure monitoring (ABPM) is used to assess the variability of blood pressure in clinical practice. Monitoring blood pressure over a 24-hour period has a better correlation with the incidence of organ complications of hypertension than blood pressure values obtained by office measurement. It also has an advantage in determining cardiovascular risk over traditional measurement $[18,19]$.

The aim of the current study was to answer the question of whether or not a 3-month comprehensive program involving the non-pharmacological treatment of obesity affects the circadian blood pressure profile.

\section{Material and methods}

The study was performed with 60 obese women, aged 20-37, who had an average body mass index (BMI) of $36 \pm 4.9 \mathrm{~kg} / \mathrm{m}^{2}$ and who declared their willingness to participate in the treatment of obesity. All women were informed about the purpose and design of the study and gave their written consent to participate.

The study protocol was approved by the Bioethical Commission of the Pomeranian Medical University at Szczecin. All patients who showed secondary forms of obesity by routine assay (e.g. thyroid cortisol test) were excluded.

Women selected for the study agreed to participate in a 3-month, comprehensive, outpatient, non-pharmacological treatment program for obesity. This program included activities with a dietician, physiotherapist and physician. The aim of the program was to reduce body weight by $5-10 \%$ using non-pharmacological methods.

Table I presents detailed clinical and biochemical characteristics of the study group.

Determinations of weight were made before treatment (0) and at 3 months on the last day of controlled, comprehensive treatment (3).

Patients reported, on an empty stomach, to an 8-9 am appointment at which anthropometric measurements were taken to assess weight and height and to calculate BMI and waist circumference. In addition, blood samples were taken for biochemical and hormonal tests including total cholesterol, HDL, LDL and triglycerides, glucose, uric acid, and TSH and insulin levels. The biochemical tests were determined by routine methods. Insulin resistance was calculated using the

Table I. Baseline characteristics of patients in the studied group

\begin{tabular}{|l|c|c|}
\hline Parameters & Mean & Range \\
\hline Age (years) & 33.5 & $20-37$ \\
\hline Body mass index [kg/m2] & 36 & $30-46$ \\
\hline Waist circumference [cm] & 104.0 & $88-126$ \\
\hline Systolic blood pressure [mm Hg] & 134.5 & $105-139$ \\
\hline Diastolic blood pressure [mm Hg] & 82.2 & $68-85$ \\
\hline Total cholesterol [mg/dl] & 192.5 & $119-267$ \\
\hline LDL [mg/dl] & 131.0 & $74-235$ \\
\hline HDL [mg/dl] & 50.0 & $27-89$ \\
\hline Triglycerides [mg/dl] & 132.3 & $33-285$ \\
\hline Fasting glucose [mg/dl] & 94.0 & $75-154$ \\
\hline Uric acid [mg/dl] & 5.6 & $2.8-11.5$ \\
\hline eGFR [ml/min/1.73 m2] & 72.4 & $60.2-90.5$ \\
\hline Plasma cortisol [nmol/] & 309 & $86-486$ \\
\hline Fasting insulin [ulU/ml] & 13.9 & $5.2-40.8$ \\
\hline IR & 3.3 & $1.14-12.1$ \\
\hline TSH [ulU/l] & 1.57 & $0.48-3.88$ \\
\hline
\end{tabular}

LDL — low density lipoprotein, HDL — high density lipoprotein, eGFR — estimated glomerular filtration, IR — insulin resistance, TSH — thyroid stimulating hormone 
Table II. Comparison of mean ( \pm SD) body mass index (BMI), waist circumference $[W C]$, blood pressure (BP) values, its short-term variability (standard deviation), fasting insulin, and insulin resistance (IR) in the studied group at baseline (0) and after 3 months of active treatment (3)

\begin{tabular}{|l|c|c|c|c|}
\hline Variable & $\mathbf{0}$ & $\mathbf{3}$ & $\Delta$ & P-value \\
\hline BMI $\left[\mathrm{kg} / \mathrm{m}^{2}\right]$ & $36.0 \pm 4.9$ & $32.0 \pm 4.9$ & $-4.5 \pm 3.3$ & $\mathrm{p}<0.001$ \\
\hline WC $[\mathrm{cm}]$ & $104.0 \pm 11.9$ & $93.0 \pm 13.7$ & $10.8 \pm 8.1$ & $\mathrm{p}<0.001$ \\
\hline 24-hour systolic blood pressure $[\mathrm{mm} \mathrm{Hg}]$ & $117 \pm 12$ & $115 \pm 11.6$ & $-1.7 \pm 8.9$ & $\mathrm{p}<0.05$ \\
\hline 24-hour diastolic blood pressure $[\mathrm{mm} \mathrm{Hg}]$ & $72 \pm 7.4$ & $71 \pm 7.6$ & $0.65 \pm 7.6$ & $\mathrm{~ns}$ \\
\hline Daytime systolic blood pressure $[\mathrm{mm} \mathrm{Hg}]$ & $120 \pm 12.2$ & $118 \pm 11.4$ & $-2.1 \pm 8.4$ & $\mathrm{p}<0.05$ \\
\hline Daytime diastolic blood pressure $[\mathrm{mm} \mathrm{Hg}]$ & $76 \pm 8.9$ & $74 \pm 7.4$ & $-1.5 \pm 6.1$ & $\mathrm{~ns}$ \\
\hline Nocturnal systolic blood pressure $[\mathrm{mm} \mathrm{Hg}]$ & $108 \pm 12.0$ & $105 \pm 11.7$ & $-2.6 \pm 8.7$ & $\mathrm{p}<0.05$ \\
\hline Nocturnal diastolic blood pressure $[\mathrm{mm} \mathrm{Hg}]$ & $63 \pm 7.9$ & $60 \pm 6.9$ & $-1.5 \pm 6.1$ & $\mathrm{~ns}$ \\
\hline Standard deviation $[\mathrm{mm} \mathrm{Hg}]$ & $11.6 \pm 2.4$ & $10.9 \pm 1.9$ & $-0.7 \pm 2.5$ & $\mathrm{~ns}$ \\
\hline Fasting insulin & $13.9 \pm 7.9$ & $9.8 \pm 5.2$ & $-4.1 \pm 6.6$ & $\mathrm{p}<0.02$ \\
\hline IR & $3.3 \pm 2.3$ & $2.3 \pm 1.3$ & $-1.1 \pm 1.7$ & $\mathrm{p}<0.001$ \\
\hline
\end{tabular}

$\Delta$ - change of parameters after active therapy

HOMA method [glucose concentration (mmol/L)] $\times$ fasting insulin $(\mathrm{uU} / \mathrm{mL} / 22.5)$.

The participants then started 24-hour Holter ambulatory pressure monitoring using an ABPM SpaceLabs 90207 measurement device. Blood pressure monitoring was based on the oscillometric method. 24-hour registration of blood pressure measurements started at 9 am and finished at the same time the next day. Measurements were made every 20 minutes during the day $(6 \mathrm{am}-10 \mathrm{pm})$ and every 30 minutes at night $(10 \mathrm{pm}-6 \mathrm{am})$, and then analysed by a computer program.

The study also evaluated the variability of the circadian average blood pressure, which was a measure of the standard deviation $(S D)$ of all measurements during the day and night and average blood pressure drop daily (N/D). The study defined dipping pattern as a decrease in the average pressure at night of at least $10 \%$, while non-dipping pattern was defined as an average pressure drop of less than $10 \%$ at night.

Statistical analysis was performed using the Statistica software. The normality of the distribution was tested using the Shapiro-Wilk method. The characteristics of independent variables with normal distribution were examined using $t$-tests with an evaluation of homogeneity of variance. Features of the abnormal distribution were examined using nonparametric tests such as the Kolmogorov-Smirnov test. Dependent variables with normal distribution were tested using $t$-tests. Dependent variables with abnormal distribution were tested using the Wilcoxon test.

The analysis of measurable values' mutual influence was performed using regression analysis for two trials. The analysis on immeasurable variables was carried out using Pearson's chi-squared test and Fisher's test for a small number of groups and the Mc-
Nemar test (nonparametric tests). All dependencies were considered statistically significant at $\mathrm{p}<0.05$.

\section{Results}

As shown in Table II, comprehensive, non-pharmacological treatment of obesity was very successful because after 3 months of treatment there was a significant reduction in participants' BMI and waist circumference. These changes were accompanied by a significant reduction in fasting insulin concentrations and a decrease in the insulin resistance index. There also were significant changes in systolic blood pressure. A small but significant reduction in circadian, daytime and nighttime systolic blood pressure values was noted. The obesity treatment had no effect on diastolic blood pressure and short-term pressure variability.

Table III presents the distribution of dippers and non-dippers in the study population before treatment and after 3 months of treatment.

Non-pharmacological treatment of obesity affected the blood pressure profile and significantly reduced $(p<0.005)$ the incidence of the disadvantages of the absence of a reduction in blood pressure during the night. Baseline measurements showed

Table III. Dippers versus non-dippers in the studied group at baseline (0) and after 3 months of active treatment (3)

\begin{tabular}{|l|c|c|}
\hline \multirow{2}{*}{} & \multicolumn{2}{|c|}{ Studied group (n=60) } \\
\cline { 2 - 3 } & Dippers & Non-dippers \\
\hline 0 & $38(63.3 \%)$ & $22(36.7 \%)$ \\
\hline 3 & $53(88.7 \%)$ & $7(11.3 \%)$ \\
\hline$\chi 2$ statistic & \multicolumn{2}{|c|}{$p<0.005$} \\
\hline
\end{tabular}


Table IV. Correlations between the changes $(\Delta)$ fasting insulin and systolic blood pressure (SBP)

\begin{tabular}{|l|c|c|}
\hline Variable & R & P-value \\
\hline$\Delta$ 24-hour SBP $[\mathrm{mm} \mathrm{Hg}]$ & 0.33 & 0.02 \\
\hline$\Delta$ Daytime SBP $[\mathrm{mm} \mathrm{Hg}]$ & 0.33 & 0.02 \\
\hline$\Delta$ Nocturnal SBP $[\mathrm{mm} \mathrm{Hg}]$ & 0.38 & 0.02 \\
\hline
\end{tabular}

$\mathrm{R}$ - refers to the Spearman rank correlation coefficient

that $63.3 \%$ of participants (38 patients) were classified as dippers while $36.7 \%$ (22 patients) were classified as non-dippers. After 3 months of treatment, $88.7 \%$ (53 patients) were classified as dippers and $11.3 \%$ (7 patients) as non-dippers.

In the study group significant positive correlations were found between the change in fasting insulin concentration and the change in systolic blood pressure: circadian $(\mathrm{r}=0.33, \mathrm{p}<0.02)$, daytime $(\mathrm{r}=0.33, \mathrm{p}<$ $0.02)$ and nighttime $(\mathrm{r}=0.38, \mathrm{p}<0.02)$ (Table IV).

\section{Discussion}

In the present study, we used 24-hour automatic monitoring to evaluate the blood pressure and its changes under the influence of a weight-loss program. For the entire study group, the mean circadian, daytime and nighttime blood pressure values were correct. After 3 months of treatment, along with weight loss, there was a small decrease in circadian, daytime and nighttime blood pressure but only systolic pressure reached statistical significance. There was no marked reduction in blood pressure, despite a decrease in body weight and other parameters evaluated through anthropometric and hormone tests.

In normotensive individuals, it is difficult to expect a reduction in blood pressure under the influence of weight loss, especially if these values are initially quite low. Probably, mechanisms are actuated to counteract such a reaction as proven by Itoh et al. [20].

Most studies have shown a link between a reduction in weight and reduction in blood pressure in patients with hypertension and developed complications of obesity [21, 22]. An interesting observation in our study has not been described in the literature. It appears that after 3 months of treatment, a significant number of non-dippers developed a favourable dipping pattern. From the literature it is known that the overnight drop in blood pressure in healthy individuals is due to the dominance of the parasympathetic system during sleep. In this aspect, it can be assumed that the dominance of the sympathetic nervous system at night leads to increased pressure and seizing of the circadian rhythm [23].

Generally, today no one denies that activities such as diet and exercise are effective methods for supporting the treatment of hypertension, and they sometimes are sufficient to eliminate the need for pharmacotherapy [24]. These are the recommendations of cardiological societies based on large, long-term, multi-centre studies such as the Framingham study $[25,26]$. The ones who benefit, however, are sick people [27]. The more features of metabolic syndrome and cardiovascular complications, the greater the effect associated with reduction of body weight and correction of metabolic disorders.

As previously reported, levels of insulin can affect blood pressure [12]. The present study found a positive correlation between insulin levels and mean systolic blood pressure circadian, daytime and nighttime. Insulin exerts a stimulatory effect on the sympathetic nervous system and an expressed impact on the systolic blood pressure values, which was confirmed by the correlation analysis.

For the obese population, the risk of cardiovascular disease is most usefully measured by BMI and waist circumference. Waist circumference is the best predictor of developing metabolic syndrome due to the good reflectivity of visceral fat, regardless of gender [28, 29]. Failing to take action to reduce weight leads to a higher degree of obesity and increasing metabolic disorders, predominantly insulin resistance, which demonstrates that it is a chronic and progressive disease.

\section{Conclusion}

A non-pharmacological, comprehensive program to treat obesity through weight reduction and a reduction of insulin resistance improves the profile of circadian systolic blood pressure and leads to the conversion from non-dipper to a favourable dipper blood pressure profile.

\section{References}

1. Bray G.A. Obesity. Handbooks of Health Care Co. Pensylvania 1998.

2. Kaplan N.M. et al. Metabolic Aspects of Hypertension. Ars Medica S.C., Gdańsk 1996.

3. Report of a WHO Consultation of Obesity. Preventing and managining the Global Epidemic. Division of noncomunicable Diseases. World Health Organization Geneva 3-5 June 1997. WHO/NUT/NDC 1998.

4. Rywik S., Broda G., Piotrowski W. et al. Epidemiologia chorób układu krążenia - program Pol-MONICA Warszawa. Kardiologia Polska 1996; 44 (supl. II): 7-36.

5. Romer T.E., Koehler B., Drzewiecka B. et al. Otyłość; W: Romer T.E. (ed.). Endokrynologia Kliniczna. Springer PWN, Warszawa 1998: 182-205. 
6. Meisler J.D., St Jear S. Summary and recommendations from American Health Foundation's Expert Panel on Healthy Weight. American Journal of Clinical Nutrition 1996 (suppl.): 474-477.

7. Zahorska-Markiewicz B. Otyłość poradnik dla lekarzy. Archi-Plus, Kraków 2002.

8. Kiortsis D.N., Tzotzas T., Giral P. et al. Changes in lipoprotein(a) levels and hormonal correlations during a weight reduction program. Nutr. Metab. Cardiovasc. Dis. 2001; 11: 153-157.

9. Oster G., Tompson D., Edelsberg J. Lifetime health and economic benefits of weight loss among obese person. Am. J. Public Health 1999; 10: 1536-1542.

10. Näslund E., Anderson I., Degerblad M. et al. Association of leptin, insulin resistance and thyroid function with long-term weigh lost in dieting obese men. J. Intern. Med. 2000: 299-308.

11. Kokot F., Adamczak M., Więcek A. et al. Does leptin play a role in the pathogenesis of essential hypertension? Kidney Blood Press. Res. 1999; 22: 154-160.

12. Landsberg L. Insulin-mediated sympathetic stimulation: role in pathogenesis of obesity - related hypertension (or, how insulin affects blood pressure, and why). J. Hypertension 2001; 19: 523-528.

13. Mayo-Smith W., Hayes C.W., Biller B.M.K. et al. Body fat distribution measured with CT: correlations in healthy subject, patient with anorexia nervosa and patient with Cushing's syndrome. Radiology 1989; 170: 515-518.

14. Mrozikiewicz-Rakowska B., Kujawska-Łuczak M., Pupek-Musialik D. Leptyna i katecholaminy w nadciśnieniu tętniczym i otyłości. Nefrologia i Dializ. Pol. 2000; 4: 252-254.

15. Mrozikiewicz-Rakowska B., Pupek-Musialik D. Czy leptyna i noradrenalina uczestniczą w kształtowaniu nadciśnienia tętniczego u osób otyłych. Nadciśnienie Tętnicze 2000; 4: 89-96.

16. Mancia G., Parati G. Ambulatory Blood Pressure Monitoring and Organ Damage. Hypertension 2000; 36: 894-900.

17. Hoshide S., Kario K., Hoshide Y et al. Associations between nondipping of nocturnal blood pressure decrease and cardiovascular target organ damage in strictly selected community; dwelling normotensives. Am. J. Hypertens. 2003; 16: 434-438.

18. Mancia G., Parati G., Henning M. et al. Relation between blood pressure variability and carotid artery damage in hypertension: baseline data from the European Lacipidine Study on Atherosclerosis (ELSA). J. Hypertens. 2001; 19: 1981-1989.

19. Steassen J.A., Thijs L., Fagard R. et al. Predicting cardiovascular risk using conventional vs ambulatory blood pressure in older patients with systolic hypertension. Systolic Hypertension in Europe Trial Investigators. JAMA 1999; 282: 539-546.

20. Itoh K., Imai K., Masuda T. et al. Relationship between changes in serum leptin levels and blood pressure by weight loss. Hypertension Res. 2002; 25: 881-886.

21. Itoh K., Imai K., Masuda K. et al. Association between blood pressure and insulin resistance in obese females during weight loss and weight rebound phenomenon, Hypertension Res. 2001; 24: 481-487.

22. Masuo K., Mikami H., Ogihara T., Tuck M.L. Weigh gain-induced blood pressure elevation. Hypertension 2000; 35: 1135-1140.

23. Furlan R., Guzzetti S., Crivellaro W. et al. Continuous 24-hour assessment of the neural regulation of systemic arterial pressure and RR variabilities in ambulant subjects. Circulation 1990; 81: 537-547.

24. Blumenthal J.A., Sherwood A., Gullette E.C. et al. Exercise and weight loss reduce blood pressure in men and woman with mild hypertension: effects of cardiovascular, metabolic, and hemodynamic functioning. Arch. Inter. Med. 2000; 160: 1947-1958.

25. Mancia G., Fagard R., Narkiewicz K. et al. 2013 ESH/ESC Guidelines for the management of arterial hypertension of the European Society of Hypertension (ESH) and of the European Society of Cardiology (ESC). J. Hypertens. 2013; 31: 1281-1357.

26. Tykarski A., Narkiewicz K., Gaciong Z. et al. 2015 Guidelines for the management of hypertension. Arterial Hypertens. 2015; 19: 53-83.

27. Reaven G.M., Linthele H., Landsberg L. Hypertension and associated metabolic abnormalities. The role of insulin resistance and the sympathoadrenal system. N. Engl. J. Med. 1996; 334: 374-380.

28. Pouliot M.-C., Desprès J.-P., Lemieux S. et al. Waist circumference and abdominal sagittal diameter: best simple antropometric index of abdominal visceral adipose tissue accumulation and related cardiovascular risk in men and women. Am. J. Cardiol. 1994; 73: 460-468.

29. Ross R., Rissanen J., Hudson R. Sensivity associated with the identification of visceral adipose tissue levels using waist circumference. Int. J. Obes. Metab. Disord. 1996; 20: 533-538. 